\title{
Association of homocysteine with ankylosing spondylitis: a systematic review and meta-analysis
}

Hui-hui Li ${ }^{1,2+}$, Xue-quan Li ${ }^{3+}$, Lin-tao Sai ${ }^{4}, Y_{i}$ Cui ${ }^{5}$, Jia-hui Xu ${ }^{6}$, Chi Zhou ${ }^{7}$, Jing Zheng ${ }^{2}$, Xing-fu Li ${ }^{8}$, Hua-xiang Liu ${ }^{8^{*}}$ and Ying-jie Zhao ${ }^{2,8^{*}}$ (i)

\begin{abstract}
Background: Hyperhomocysteinemia is associated with autoimmune diseases such as ankylosing spondylitis (AS), systemic lupus erythematosus (SLE), and rheumatoid arthritis (RA). Current findings regarding plasma/serum homocysteine (HCY) levels in AS patients are inconsistent. This study aims to systematically evaluate the association between circulating HCY levels and AS.

Methods: Online electronic databases (PubMed, Web of Science, Embase, ScienceDirect, China National Knowledge Infrastructure (CNKI), and Wanfang data) were used to retrieve all relevant articles published up to May 7, 2020. The pooled standardized mean difference (SMD) with 95\% confidence interval (Cl) was calculated using the randomeffect model, Stata16 software.

Results: Nine articles containing 778 AS patients and 522 controls were included in this meta-analysis. No significant differences in HCY levels were found between AS and control groups (pooled SMD $=0.46,95 \% \mathrm{Cl}=-$ 0.30 to $1.23, P=0.23)$. However, subgroup analysis suggested that HCY levels were significantly higher $(P<0.05)$ in the AS group treated with methotrexate (MTX) compared with the control group. In contrast, HCY levels were significantly $(P<0.05)$ lower in the AS group receiving anti-TNF-a treatment compared with the control group. No significant differences were detected between HCY levels and disease activity scores (Bath AS disease activity index, BASDAI), and methylenetetrahydrofolate reductase (MTHFR) C677T genotype.

Conclusion: This meta-analysis indicates that HCY levels are similar between AS and controls, and do not correlate with disease activity. However, different medical treatments cause fluctuations of circulating HCY levels in AS patients. Further and larger-scale studies are needed to confirm these findings.

Trial registration: This study was registered at international prospective register of systematic reviews (PROSPERO), registration number: CRD42020184426.
\end{abstract}

Keywords: Homocysteine, Meta-analysis, Ankylosing spondylitis, Controls

\footnotetext{
* Correspondence: |zzlhx63@163.com; yzhaoqilu@sdu.edu.cn

${ }^{+}$Hui-hui Li and Xue-quan Li contributed equally to this work.

${ }^{8}$ Department of Rheumatology, Qilu Hospital, Cheeloo College of Medicine,

Shandong University, Jinan 250012, Shandong, China

2Department of Obstetrics and Gynecology, University of Wisconsin-Madison,

Madison, WI 53715, USA

Full list of author information is available at the end of the article
}

(c) The Author(s). 2021 Open Access This article is licensed under a Creative Commons Attribution 4.0 International License, which permits use, sharing, adaptation, distribution and reproduction in any medium or format, as long as you give appropriate credit to the original author(s) and the source, provide a link to the Creative Commons licence, and indicate if changes were made. The images or other third party material in this article are included in the article's Creative Commons licence, unless indicated otherwise in a credit line to the material. If material is not included in the article's Creative Commons licence and your intended use is not permitted by statutory regulation or exceeds the permitted use, you will need to obtain permission directly from the copyright holder. To view a copy of this licence, visit http://creativecommons.org/licenses/by/4.0/. 


\section{Background}

Ankylosing spondylitis (AS) is an immune-associated systemic inflammatory rheumatic disease characterized primarily by progressive inflammation of the spine, sacroiliitis, and various extra-articular manifestations such as anterior uveitis, inflammatory bowel disease, subclinical inflammation of the gut, psoriasis, airway disease, and interstitial lung abnormalities [1-6]. Increasing evidence indicates that AS increases cardiovascular morbidity and mortality as compared with the general population [7].

Homocysteine (HCY) is a sulfur-containing amino acid formed during the metabolism of methionine to cysteine [8]. HCY levels are elevated in many acquired disorders such as cardiovascular disease, cerebrovascular disease, dementia-type disorders, osteoporosis-associated fractures, chronic renal disease, autoimmune diseases, inflammatory diseases, deficiency of vitamins B6, B12, or folic acid, as well as during anti-folate drug therapy [919] Elevated HCY may trigger autoimmune reactions through binding and structurally modifying specific proteins, resulting in the formation of neoantigens that are potentially relevant either in the onset of specific autoimmune diseases or in the progression of the associated cardiovascular damage [20].

HCY could modify Human Leukocyte Antigens-B27 (HLA-B27) through forming a disulfide bond with an unpaired cysteine residue at position 67 (Cys67) of the HLA-B27 heavy chain [21], and subsequently, be destroyed by the abnormal autoimmunological reactions [21]. An in vitro study has shown HCY could induce specific cytotoxic T lymphocytes (CTLs), and HLA-B27restricted $\mathrm{HCY}$-specific CTLs are more often found in B27-positive patients [21]. HCY-treated B cells can be specifically lysed by CTLs in patients with AS and reactive arthritis (ReA) [21]. Evidence also suggests that Salmonella infection could lead to the modification of HLA antigens and such modified HLA antigens can be recognized by HCY-specific CTLs [21]. Collectively, these findings support the notion that $\mathrm{HCY}$ may be involved in the mechanism underlying HLA-B27-associated AS.

Previous studies have shown both pro-inflammatory and anti-inflammatory properties of $\mathrm{HCY}$ [22-25]. An association between hyperhomocysteinemia and inflammation has been identified in human and experimental animal models $[17,26]$. In vitro, $\mathrm{HCY}$ induces mRNA and protein expression of the inflammatory cytokines including tumor necrosis factor (TNF)- $\alpha$, Interleukin (IL)-1 $\beta$, IL6 , IL-8, and IL-12 in human monocytes [27]. Correlations of HCY with soluble $75-\mathrm{kDa}$ TNF-receptor (sTNF-R75) has also been found in RA patients [28]. HCY may activate nuclear factor-kappaB (NF-kB) activation [29], which may lead to increased chemokine expression in vascular smooth muscle cells (VSMCs) and macrophages [30, 31].
$\mathrm{HCY}$, at the range of physiologic concentrations, enhances monocyte proliferation in vitro [27]. HCY may also be involved in corona virus disease-19 (COVID-19) infection via transsulfuration pathway [32], which is catalyzed by cystathionine $\beta$-synthase and cystathionine $\gamma$-lyase (CSE) and serves as a modulator of inflammation [33]. Nevertheless, HCY significantly ameliorates cholesterol-induced inflammation in an in vivo hypercholesterolemic rat model possibly by acting on the tissue plasminogen activator (tPA)-induced process [24].

Based on the facts that AS is associated with increased cardiovascular morbidity and mortality, the high level of $\mathrm{HCY}$ is considered a well-known risk factor for cardiovascular disease $[7,8]$, it is necessary to define the association between HCY and AS. However, the conclusions of $\mathrm{HCY}$ levels reported in AS patients are inconsistent. Several studies reported high levels of serum/plasma HCY levels in AS patients [34-38]. In contrast, others claimed that HCY levels in AS patients were similar or lower compared with control patients [16, 39-41]. Therefore, in this meta-analysis, we aim to determine $\mathrm{HCY}$ levels in AS and investigate the correlation between HCY levels and disease activity and medical treatments.

\section{Methods}

\section{Search strategy}

We performed electronic literature searches in PubMed, Web of Science, Embase, ScienceDirect, China National Knowledge Infrastructure (CNKI), and Wanfang data up to May 7, 2020 with keywords including Homocysteine, Hyperhomocysteinemia, Ankylosing, and Spondylitis.

\section{Inclusion criteria and exclusion criteria}

The article inclusion criteria were as follows: (1) a casecontrol or cross-sectional study; (2) based on adults; (3) AS patients must conform to the American College of Rheumatology (ACR) criteria [42] or European Spondyloarthropathy Study Group (ESSG) criteria for classification of spondylarthropathies [43]; and (4) serum or plasma $\mathrm{HCY}$ concentrations of both patients and controls were available. Articles were not limited to geographic location or language of publication. Articles excluded in this meta-analysis were as follows: (1) reviews; (2) animal studies; and (3) lack of controls. A detailed flow chart of article inclusion and exclusion process was presented in Fig. 1. All articles obtained electronically were examined independently by two researchers.

\section{Data extraction and quality assessment}

Each of the enrolled articles was extracted by two researchers independently for the following information: first author's name, year of publication, study design, the 


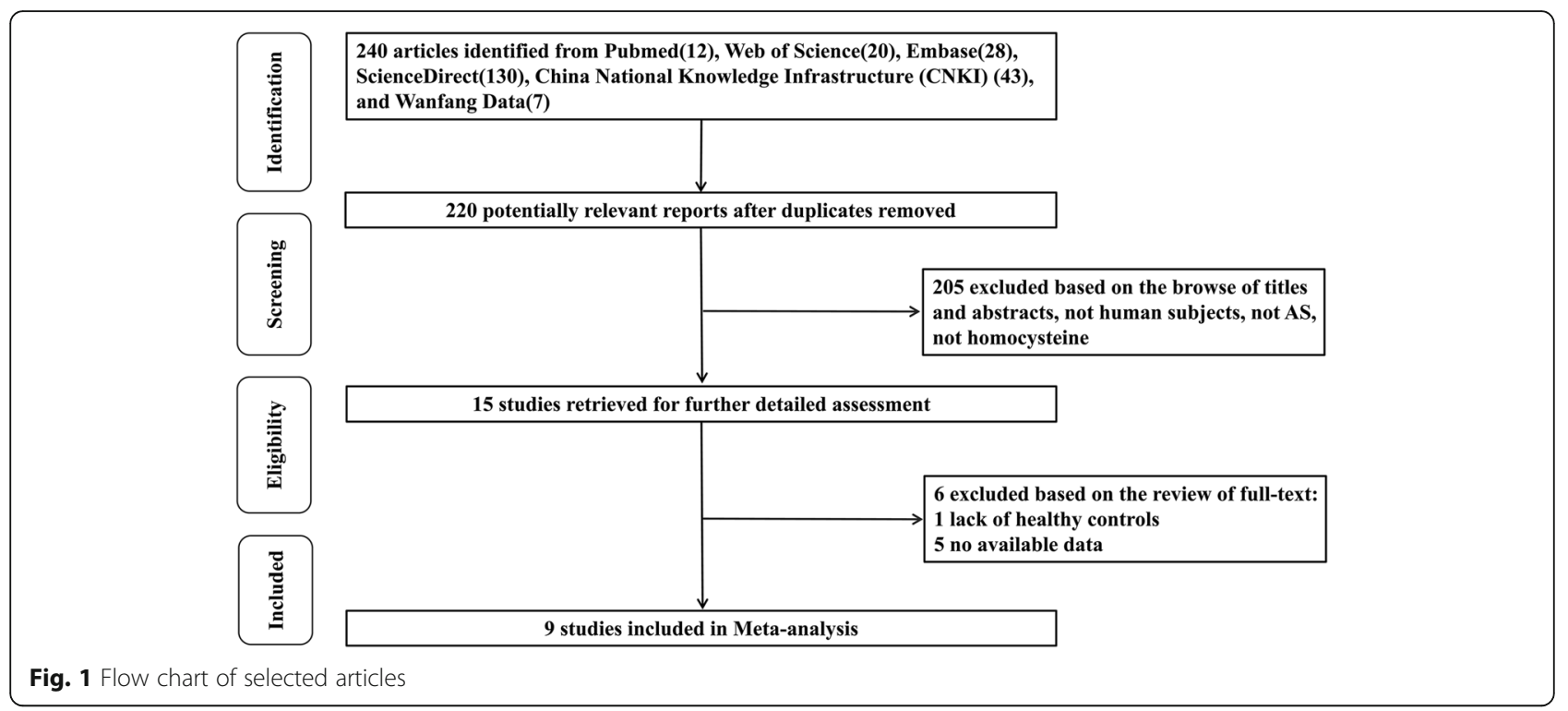

language of the article, region, participants' characteristics (age and gender), disease activity score (Bath AS disease activity index, BASDAI) [44], disease duration, mean \pm SD or mean \pm SEM of the plasma/serum HCY levels in AS and control groups, measurement method, sample type, and any other relevant information. Metaanalysis was performed according to the Preferred Reporting Items for Systematic Reviews and MetaAnalysis (PRISMA) guidelines [45]. Any disagreement on study inclusion or data extraction was discussed with a third reviewer to reach a consensus. The NewcastleOttawa quality assessment scale (NOS) was used to assess the methodological quality of eligible studies [46].

\section{Statistical analysis}

The extracted results that were presented in median, standard error, range, and interquartile range were converted to mean and standard deviation (SD) [47, 48]. The mean and SD (mean \pm SD) were extracted or estimated in each study. For each study, the standardized mean difference (SMD) and 95\% confidence intervals $(95 \% \mathrm{CI})$ were elaborately shown by the forest plot. Cochrane $Q$ statistics (chi-square test, $\chi^{2}$ ) were employed to evaluate statistical heterogeneity. The $I$ square $\left(I^{2}\right)$ statistics was used to further assess the extent of heterogeneity $\left(I^{2}=([Q-d f]) \times 100 \%\right)$ [49]. Based on the Cochrane Handbook for Systematic Reviews' recommendations, we interpreted $I^{2}$ statistic between 0 and $40 \%$ as representing an insignificant amount of heterogeneity; 30 to $60 \%$ as moderate heterogeneity; 50 to $90 \%$ as substantial heterogeneity; and 75 to $100 \%$ as considerable heterogeneity [50]. When $P<0.05$ for the $Q$ test or $I^{2}>50$, it indicated that heterogeneity was significant in the study. Assuming that the heterogeneity is significant, the random-effects model was adopted to pool the SMD value; or else, the fixed-effect model was adopted. Subgroup analysis was performed to discover the sources of heterogeneity. Sensitivity analysis was also executed to detect studies that extremely contributed to the observed heterogeneity. This was done by omitting each study one after the other to measure its impact on the summary estimate. To evaluate the publication bias, Egger's and Begg's tests were used. Stata 16 software was used in this meta-analysis to perform statistical analysis.

\section{Results}

Publication search and study characteristics

Out of a total of 15 relevant studies found, 9 original studies met our inclusion criteria and were selected for this meta-analysis. These 9 studies were published between 2005 and 2020 and included 778 AS patients and 522 controls [16, 34-41]. Of the 9 studies, 4 were conducted in Asia, 3 in Asia-Europe (Turkey), 1 in Europe, and 1 in South America. As of the controls, 1 study included non-inflammatory low back pain [39], 1 included osteoarthritis or soft tissue rheumatism [41], and the other 7 included healthy controls [16, 34-38, 40]. Our methodological quality assessment showed the NOS scores of included studies ranged from 7 to 8 . The characteristics of the included studies are summarized in Table 1. Extracted data on circulating HCY levels were presented in Table 2.

\section{Results of meta-analysis}

Publication bias was assessed by Egger's regression test $(t=-0.74, P=0.48)$ and Begg's test $(z=-0.31, P=1.25)$, suggesting no publication bias present. Among the enrolled studies, significant heterogeneity was observed 
Table 1 Characteristics of individual studies included

\begin{tabular}{|c|c|c|c|c|c|c|c|c|c|c|c|c|c|}
\hline \multirow{2}{*}{$\begin{array}{l}\text { First } \\
\text { author, } \\
\text { year }\end{array}$} & \multirow[t]{2}{*}{ Region } & \multicolumn{5}{|l|}{ AS } & \multicolumn{3}{|l|}{ Control } & \multirow[b]{2}{*}{$\begin{array}{l}\text { Assay } \\
\text { method, } \\
\text { sample }\end{array}$} & \multirow[b]{2}{*}{$\begin{array}{l}\text { Study } \\
\text { type }\end{array}$} & \multirow[b]{2}{*}{$\begin{array}{l}\text { Criteria for } \\
\text { the } \\
\text { classification }\end{array}$} & \multirow[b]{2}{*}{ NOS } \\
\hline & & $\begin{array}{l}\begin{array}{l}\text { Age } \\
\text { (year) }\end{array} \\
\text { (mean } \pm \\
\text { sd) }\end{array}$ & BMI & $\begin{array}{l}\text { Sex } \\
\text { ratio } \\
(M / F)\end{array}$ & BASDAI & $\begin{array}{l}\text { Duration } \\
\text { (year) } \\
\text { (mean } \pm \text { sd) }\end{array}$ & 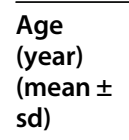 & BMI & $\begin{array}{l}\text { Sex } \\
\text { ratio } \\
\text { (M/F) }\end{array}$ & & & & \\
\hline $\begin{array}{l}\text { Shu JL, } \\
2020 \text { [16] }\end{array}$ & $\begin{array}{l}\text { Mainland } \\
\text { China }\end{array}$ & $41.6 \pm 8.6$ & NA & $30 / 5$ & NA & NA & $\begin{array}{l}39.7 \pm \\
14.4\end{array}$ & NA & $36 / 5$ & NA & CS & $A C R$ & 7 \\
\hline $\begin{array}{l}\text { Geçene M, } \\
2013 \text { [39] }\end{array}$ & Turkey & $36.7 \pm 4.8$ & $\begin{array}{l}24.9 \pm \\
3.1\end{array}$ & $50 / 0$ & $2.4 \pm 1.7$ & NA & $36.3 \pm 4.7$ & $\begin{array}{l}25.0 \pm \\
3.0\end{array}$ & $50 / 0$ & $\begin{array}{l}\text { HPLC, } \\
\text { plasma }\end{array}$ & CS & $A C R$ & 7 \\
\hline $\begin{array}{l}\text { Mao N, } \\
2012 \text { [34] }\end{array}$ & $\begin{array}{l}\text { Mainland } \\
\text { China }\end{array}$ & NA & NA & NA & NA & NA & NA & NA & NA & $\begin{array}{l}\text { ELISA, } \\
\text { plasma }\end{array}$ & CS & $A C R$ & 7 \\
\hline $\begin{array}{l}\text { Capkin E, } \\
2012 \text { [40] }\end{array}$ & Turkey & $\begin{array}{l}36.4 \pm \\
11.2\end{array}$ & NA & $88 / 20$ & $3.7 \pm 1.6$ & $8.4 \pm 5.6$ & $\begin{array}{l}38.2 \pm \\
13.0\end{array}$ & NA & $49 / 16$ & $\begin{array}{l}\text { ELISA, } \\
\text { plasma }\end{array}$ & CS & $A C R$ & 7 \\
\hline $\begin{array}{l}\text { Başkan BM, } \\
2009 \text { [35] }\end{array}$ & Turkey & $\begin{array}{l}40.1 \pm \\
11.0\end{array}$ & NA & NA & $4.2 \pm 1.7$ & $10.0 \pm 7.7$ & $38.1 \pm 0.6$ & NA & NA & NA & CS & $A C R$ & 7 \\
\hline $\begin{array}{l}\text { Gonzalez- } \\
\text { Lopez L, } \\
2008 \text { [36] }\end{array}$ & Mexico & $39.9 \pm 8.4$ & $\begin{array}{l}26.0 \pm \\
2.8\end{array}$ & $73 / 24$ & $5.4 \pm 2.1$ & $7.8 \pm 6.0$ & $38.9 \pm 7.8$ & $\begin{array}{l}25.8 \pm \\
4.2\end{array}$ & $73 / 24$ & $\begin{array}{l}\text { FPIA, } \\
\text { Serum }\end{array}$ & CSS & $A C R$ & 8 \\
\hline $\begin{array}{l}\text { Wei JC, } \\
2007 \text { [37] }\end{array}$ & $\begin{array}{l}\text { Taiwan, } \\
\text { China }\end{array}$ & NA & NA & NA & NA & NA & NA & NA & NA & $\begin{array}{l}\text { ELISA, } \\
\text { plasma }\end{array}$ & CSS & $A C R$ & 7 \\
\hline $\begin{array}{l}\text { Malesci D, } \\
2007 \text { [41] }\end{array}$ & Italy & $\begin{array}{l}47.6 \pm \\
11.8\end{array}$ & $\begin{array}{l}29.5 \pm \\
4.4\end{array}$ & $21 / 3$ & $2.7 \pm 1.8$ & $18.5 \pm 10.8$ & $49.6 \pm 6.0$ & NA & $16 / 3$ & NA & CS & ACR\&ESSG & 8 \\
\hline $\begin{array}{l}\text { Xu XY, } 2005 \\
\text { [38] }\end{array}$ & $\begin{array}{l}\text { Mainland } \\
\text { China }\end{array}$ & $\begin{array}{l}32.1 \pm \\
13.7\end{array}$ & NA & $44 / 16$ & NA & NA & $\begin{array}{l}30.8 \pm \\
19.7\end{array}$ & NA & $30 / 32$ & $\begin{array}{l}\text { FPIA, } \\
\text { plasma }\end{array}$ & CS & $A C R$ & 7 \\
\hline
\end{tabular}

AS Ankylosing spondylitis, BMI Body mass index, BASDAI Bath AS disease activity index, NOS Newcastle-Ottawa Scale, NA Not available, HPLC High performance liquid chromatography, ELISA Enzyme-linked immunosorbent assays, FPIA Fluorescence polarization immunoassay, CS Case control, CSS Cross-sectional study, ACR American College of Rheumatology, ESSG European Spondyloarthropathy Study Group

$\left(I^{2}=97.3 \%, P<0.01\right)$. Sensitivity analysis by sequentially omitting individual studies did not significantly change the pooled results, suggesting that these results were stable (Fig. 2).

\section{$\mathrm{HCY}$ levels and subgroup analysis}

The random-effect model was used for the analysis of results in this study based on the result that significant heterogeneity was observed among the enrolled studies $(P<0.01)$. There were no significant differences in

Table 2 Extracted data on HCY levels of 9 studies included

\begin{tabular}{|c|c|c|c|c|c|c|}
\hline \multirow[t]{2}{*}{ First author, year } & \multicolumn{3}{|c|}{ AS $(\mu \mathrm{mol} / \mathrm{L})$} & \multicolumn{3}{|c|}{ Control $(\mu \mathrm{mol} / \mathrm{L})$} \\
\hline & $N$ & Mean & SD & $N$ & Mean & SD \\
\hline Shu JL, 2020 [16] & 35 & 12.27 & 7.52 & 41 & 13.94 & 3.73 \\
\hline Geçene M, 2013 [39] & 50 & 14.26 & 9.96 & 50 & 11.81 & 5.53 \\
\hline Mao N, 2012 [34] & 200 & 18.71 & 2.42 & 120 & 10.97 & 2.93 \\
\hline Capkin E, 2012 [40] & 108 & 18.90 & 8.70 & 65 & 23.80 & 5.80 \\
\hline Başkan BM, 2009 [35] & 92 & 17.18 & 12.47 & 58 & 13.16 & 4.09 \\
\hline Gonzalez-Lopez L, 2008 [35] & 97 & 11.35 & 5.39 & 97 & 9.61 & 2.33 \\
\hline Wei JC, 2007 [37] & 112 & 9.91 & 3.47 & 10 & 8.60 & 1.20 \\
\hline Malesci D, 2007 [41] & 24 & 8.70 & 2.00 & 19 & 9.10 & 1.20 \\
\hline Xu XY, 2005 [38] & 60 & 16.47 & 6.50 & 62 & 12.24 & 3.58 \\
\hline
\end{tabular}

HCY Homocysteine, N Number, SD Standard deviation circulating HCY levels between AS patients and controls (pooled $\mathrm{SMD}=0.46,95 \% \mathrm{CI}=-0.30$ to $1.23, P=0.23$ ) (Fig. 3). Subgroup analysis stratified by region, sample size, disease activity, smoker or not, methylenetetrahydrofolate reductase (MTHFR) C677T genotype, and medication treatment were performed (Table 3). As of disease activity, 1 study defined that patients with BASDAI values $\geq 4$ were regarded as active AS group [40]. Two studies defined that patients with BASDAI values > 3 and ESR $>20 \mathrm{~mm} / \mathrm{h}$ were regarded as active AS group $[35,37]$. To conduct medication treatment subgroup analysis, we analyzed four subgroups: nonsteroidal antiinflammatory drugs (NSAIDs), sulfasalazine (SSZ), SSZ + methotrexate (MTX), and anti-TNF- $\alpha$. In SSZ + MTX treatment subgroup, $\mathrm{HCY}$ levels in AS patients were significantly higher than those in controls (pooled $\mathrm{SMD}=0.915,95 \% \mathrm{CI}=0.312$ to $1.518, P=0.003)$. In anti-TNF- $\alpha$ treatment subgroup, HCY levels in AS patients were significantly lower than in controls (pooled $\mathrm{SMD}=-0.774,95 \% \mathrm{CI}=-1.163$ to $-0.385, P<0.001$ ). Meanwhile, no significant differences of HCY levels between AS patients and controls were detected in NSAI Ds or SSZ treatment subgroup. In particular, no significant correlation between $\mathrm{HCY}$ levels and disease activity, and MTHFR C677T genotype, as well as in region, sample size, and smoking subgroups was detected. 


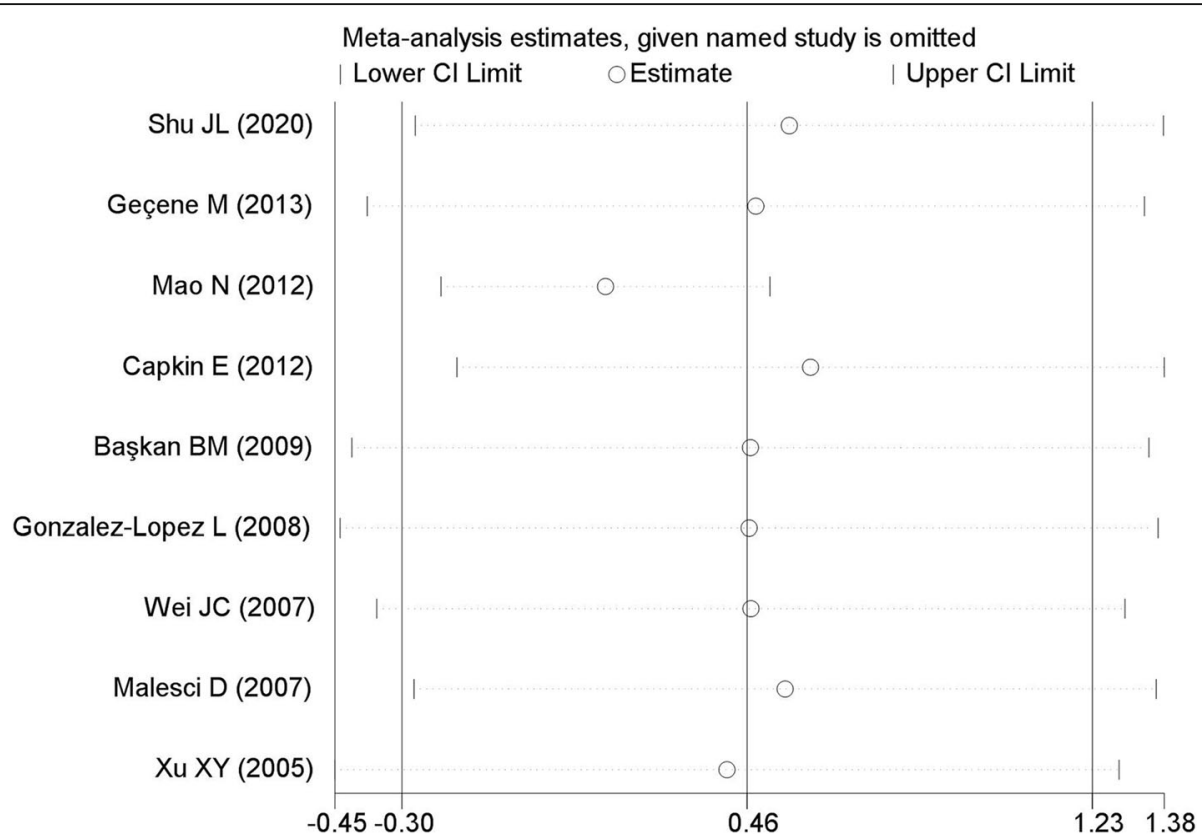

Fig. 2 Sensitivity analysis of the included studies. The two vertical axes, vertical middle axis, hollow circles, and two ends of the dotted lines respectively represent $95 \%$ confidence interval, overall odd ratio, pooled odd ratios, and $95 \%$ confidence interval

\section{Discussion}

A positive relationship was reported between circulating HCY levels and certain clinical features of rheumatoid arthritis (RA), such as higher disease activity [51] and higher radiological damage [52]. A significant correlation also exists between HCY levels and the various indexes of disease activity of systemic lupus erythematosus (SLE), such as erythrocyte sedimentation rate, antidouble-stranded DNA, complement levels in patients of SLE [15]. Intensive steroid therapy in RA patients results in significant HCY reduction [53]. In contrast, Shu et al. has reported that $\mathrm{HCY}$ levels are not associated with $\mathrm{C}$ -

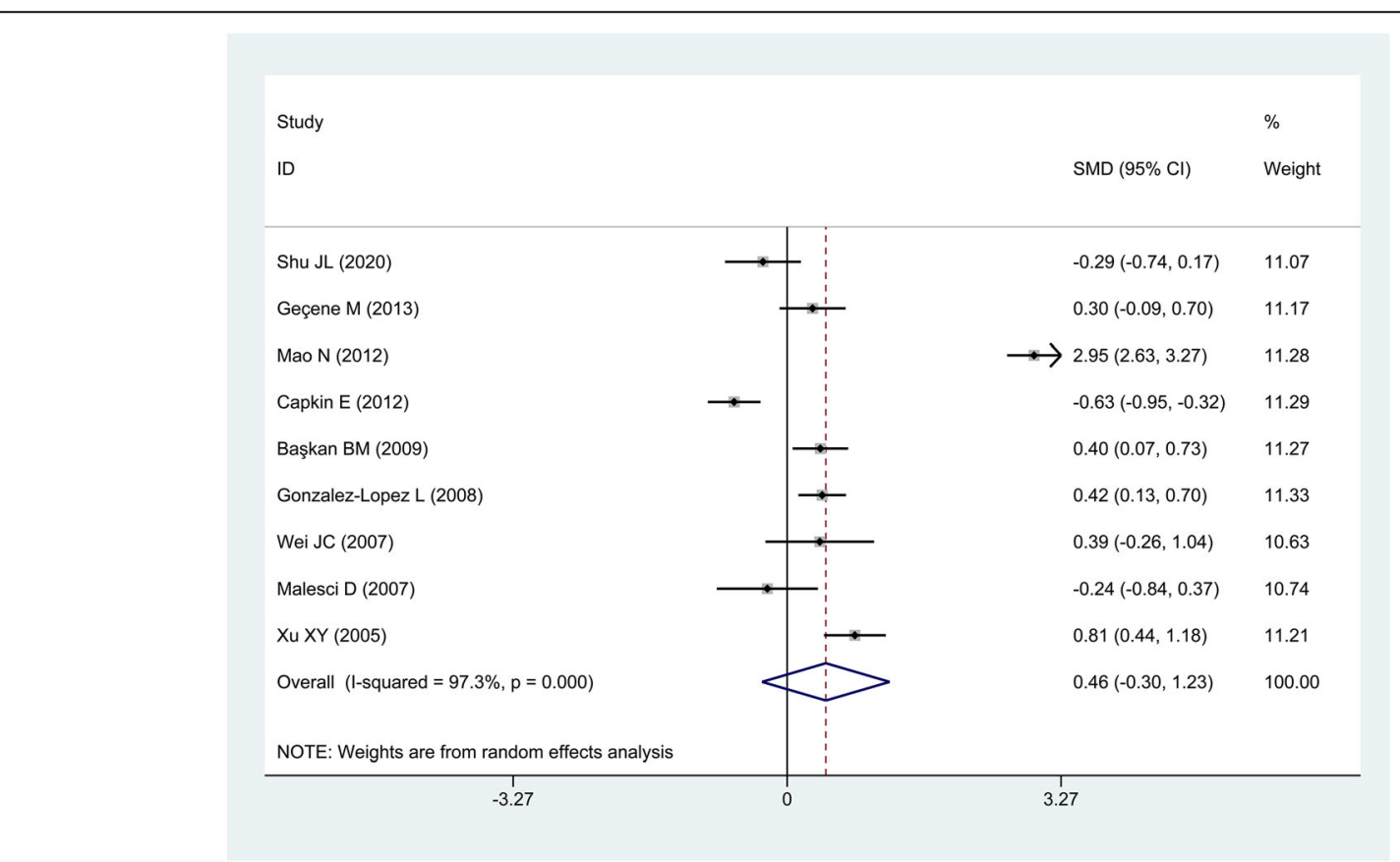

Fig. 3 Forest plot of 9 studies in HCY levels for AS patients versus controls, based on random effects model 
Table 3 Subgroup analysis of HCY levels in AS

\begin{tabular}{|c|c|c|c|c|c|c|c|}
\hline \multirow[t]{2}{*}{ Subgroups } & & \multirow[t]{2}{*}{$N$} & \multirow[t]{2}{*}{ SMD $(95 \% \mathrm{Cl})$} & \multirow[t]{2}{*}{$Z$} & \multirow[t]{2}{*}{$P$} & \multicolumn{2}{|c|}{ Heterogeneity test } \\
\hline & & & & & & $P$ & $I^{2}(\%)$ \\
\hline \multirow[t]{4}{*}{ Region } & Asia & 4 & $0.974(-0.573,2.521)$ & 1.23 & 0.217 & $<0.001$ & $98.1 \%$ \\
\hline & Asia + Europe (Turkey) & 3 & $0.018(-0.661,0.698)$ & 0.05 & 0.958 & $<0.001$ & $91.4 \%$ \\
\hline & Europe/America & 2 & $0.148(-0.484,0.780)$ & 0.46 & 0.646 & 0.055 & $73.0 \%$ \\
\hline & Combined & 9 & $0.463(-0.300,1.226)$ & 1.19 & 0.234 & $<0.001$ & $97.3 \%$ \\
\hline \multirow[t]{3}{*}{ Sample size } & $\geq 50$ & 6 & $0.708(-0.283,1.700)$ & 1.40 & 0.162 & $<0.001$ & $98.1 \%$ \\
\hline & $<50$ & 2 & $-0.269(-0.632,0.093)$ & 1.46 & 0.145 & 0.891 & $0.0 \%$ \\
\hline & Combined & 8 & $0.471(-0.355,1.298)$ & 1.12 & 0.264 & $<0.001$ & $97.6 \%$ \\
\hline \multirow[t]{3}{*}{ Disease activity } & active & 3 & $0.048(-0.904,1.000)$ & 0.10 & 0.921 & $<0.001$ & $92.0 \%$ \\
\hline & inactive & 3 & $0.078(-0.733,0.889)$ & 0.19 & 0.851 & $<0.001$ & $89.0 \%$ \\
\hline & Combined & 6 & $0.059(-0.488,0.606)$ & 0.21 & 0.833 & $<0.001$ & $88.5 \%$ \\
\hline \multirow[t]{3}{*}{ Smoking } & Smoker & 1 & $0.497(-0.066,1.060)$ & 1.73 & 0.084 & NA & NA \\
\hline & Non-smoker & 1 & $0.201(-0.355,0.757)$ & 0.71 & 0.478 & NA & NA \\
\hline & Combined & 2 & $0.347(-0.048,0.743)$ & 1.72 & 0.085 & 0.464 & $0.0 \%$ \\
\hline \multirow[t]{4}{*}{ MTHFR C677T genotype } & $\mathrm{CC}$ & 2 & $1.599(-0.864,4.062)$ & 1.27 & 0.203 & $<0.001$ & $98.1 \%$ \\
\hline & $C T$ & 2 & $1.693(-1.256,4.642)$ & 1.13 & 0.260 & $<0.001$ & $97.7 \%$ \\
\hline & $\pi$ & 2 & $2.771(-1.141,6.682)$ & 1.39 & 0.165 & $<0.001$ & $92.2 \%$ \\
\hline & Combined & 6 & $1.992(0.663,3.320)$ & 2.94 & 0.003 & $<0.001$ & $95.7 \%$ \\
\hline \multirow[t]{5}{*}{ Treatment } & NSAIDs & 2 & $-0.365(-1.020,0.291)$ & 1.09 & 0.275 & 0.092 & $64.8 \%$ \\
\hline & SSZ & 2 & $0.024(-0.872,0.920)$ & 0.05 & 0.958 & 0.003 & $88.7 \%$ \\
\hline & $\mathrm{SSZ}+\mathrm{MTX}$ & 1 & $0.915(0.312,1.518)$ & 2.97 & 0.003 & NA & NA \\
\hline & Anti-TNF-a & 1 & $-0.774(-1.163,-0.385)$ & 3.90 & $<0.001$ & NA & NA \\
\hline & Combined & 6 & $-0.094(-0.634,0.445)$ & 0.34 & 0.732 & 0.000 & $87.7 \%$ \\
\hline
\end{tabular}

HCY Homocysteine, NA Not available, MTHFR Methylenetetrahydrofolate reductase, NSAIDs Non-steroidal anti-inflammatory drugs, SSZ Sulfasalazine, MTX Methotrexate, TNF Tumor necrosis factor

reactive protein (CRP), erythrocyte sedimentation rate (ESR), rheumatoid factor (RF), and anti-citrullinated protein antibody (ACPA) in RA [16]. Our study indicates no significant correlation between $\mathrm{HCY}$ levels and AS disease activity. However, subgroup analysis suggests that elevated HCY levels are associated with the AS group treated with MTX. This association may be attributed to the inhibitory effect of MTX on the levels of folate $[19,40]$. Specifically, MTX treatment influences folate metabolism in RA patients, leading to a decrease in serum folate levels and a rise in HCY levels [54]. However, while MTX increases plasma $\mathrm{HCY}$ levels, folate supplementation decreases HCY concentrations, protecting against potential cardiovascular risks in RA patients [55]. In clinical practice, folate supplement is used to reduce side-effect incidence of MTX in RA patients, suggesting that folate supplement should be considered for AS patients treated with MTX. Of the 9 studies included in this analysis, 4 recruited AS patients on MTX [35-37, 41], 2 of which used folate supplementation $[35,36]$. Of the other 5 studies, 3 didn't use MTX [38-40] and 2 didn't mention any treatment method [16, 34].

SSZ has also been reported to have anti-folate properties [56], implying SSZ may increase HCY levels in patients. This is supported by the observation that plasma $\mathrm{HCY}$ levels was increased significantly in AS patients under SSZ, and SSZ/MTX combination treatment [37]. However, our subgroup analysis showed no significant differences in HCY levels in AS patients treated with SSZ compared with controls. In addition, HCY levels were significantly lower in AS group treated with antiTNF- $\alpha$ regimen. These findings support the note that different medical treatments may influence HCY levels. However, the reasons attributed to the above results remain unknown. In this meta-analysis, two studies contain HCY levels and treatment methods in AS patients $(n=198)[35,40]$. The above findings might be a result of the small sample size employed in the individual studies. Further studies are needed to confirm these findings.

HCY levels are known to be controlled by methylenetetrahydrofolate reductase (MTHFR), which is a key 
enzyme in HCY metabolism [57]. MTHFR C677T polymorphism causes a thermolability of MTHFR, reducing its enzymatic activity [57]. Such a reduction inhibits the formation of 5-methyltetrahydrofolate, which serves as a methyl donor during the remethylation of $\mathrm{HCY}$ to methionine [57]. Studies indicated that the TT genotype of the MTHFR C677T polymorphism exhibits higher plasma $\mathrm{HCY}$ concentrations than CT heterozygotes and CC homozygotes [58, 59]. Besides, Mao et al. reported that high plasma HCY levels are associated with MTHF $\mathrm{R}$ 677TT polymorphism as compared with the $\mathrm{CC}$ or CT genotype in AS patients [34]. In this meta-analysis, subgroup analysis showed no significant correlation between all 3 genotypes of the MTHFR C677T polymorphism and HCY levels in AS. This result agrees with the previous report which showed no association between MTHFR 677TT polymorphism and plasma HCY levels in obese children and adolescents [60] and no statistically significant differences according to the frequency of MTHFR C677T polymorphism between AS patients and controls [39].

As a well-known risk factor for cardiovascular disease, $\mathrm{HCY}$ can mediate the development of the cardiovascular disease by acting adversely on vascular endothelium and smooth muscle cells [61]. Elevated HCY levels may also enhance oxidative stress and inflammation of vascular endothelial cells and reduce the production and bioavailability of nitric oxide (a strong relaxing factor) by endothelium [62]. HCY stimulates the proliferation of vascular smooth muscle cells, synthesis of collagen, and deterioration of arterial wall elastic material [61]. AS also significantly increases risks of myocardial infarction and stroke [63]. Multiple factors contribute to such increased cardiovascular risk. In this regard, systemic inflammation and high disease activity play pivotal roles in the process [64]. Another possible factor is the proatherogenic profile of AS patients who were smokers and/or hypertensive with a poor atherogenic lipid profile [64]. Recommendations from EULAR pointed out that disease activity should be controlled optimally to lower CVD risk in all patients with AS, RA or psoriatic arthritis (PsA) [65]. In addition, MTX treatment decreases the acute myocardial infarction (AMI) among RA patients [66], suggesting that MTX plays a role in protecting patients from CVD risk, possibly via controlling the inflammatory process although MTX elevates HCY levels.

To our knowledge, this is the first meta-analysis that provides evidence of HCY levels in AS patients compared with controls. We are able to extract valid and accurate results from the individual articles and use a sample size of 778 patients of AS and 522 of controls for $\mathrm{HCY}$ levels to increase the statistical power and resolution of our analysis compared with the individual studies. However, several limitations are recognized. First, the significant heterogeneity in our meta-analysis may restrict the generalization of the pooled result. Second, due to the lack of sufficient data to perform more exhaustive subgroup analysis and meta-regression, the origin of heterogeneity could not be fully revealed.

\section{Conclusions}

This meta-analysis suggests that HCY may partially participate in the pathogenesis of AS, although it is not a major contributing factor. Further and larger studies are needed to confirm these findings.

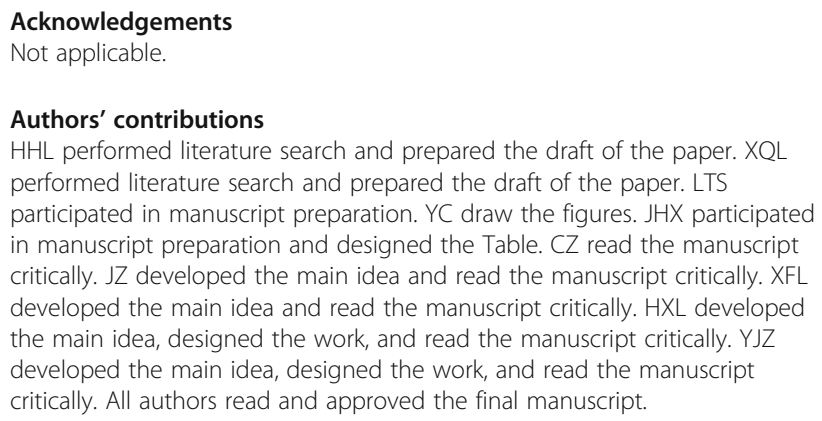

\section{Funding}

This work was supported by Key Technology Research and Development Program of Shandong (CN) (2018GSF118071 to YJZ, and 2018GSF118025 to $H H L)$.

\section{Availability of data and materials}

The datasets used and/or analyzed during the current study are available from the corresponding author on reasonable request.

\section{Declaration}

Ethics approval and consent to participate

Not applicable.

Consent for publication

Not applicable.

\section{Competing interests}

The authors declare that they have no competing interests.

\section{Author details}

'Department of Obstetrics and Gynecology, Qilu Hospital, Cheeloo College of Medicine, Shandong University, Jinan 250012, Shandong, China.

${ }^{2}$ Department of Obstetrics and Gynecology, University of Wisconsin-Madison, Madison, WI 53715, USA. ${ }^{3}$ Department of Gastroenterology, Shouguang People's Hospital, Shouguang 262700, Shandong, China. ${ }^{4}$ Department of Infectious Diseases, Qilu Hospital, Cheeloo College of Medicine, Shandong University, Jinan 250012, Shandong, China. ${ }^{5}$ Department of Intensive Care Unit, Qilu Hospital, Cheeloo College of Medicine, Shandong University, Jinan 250012, Shandong, China. 'Shandong First Medical University \& Shandong Academic of Medical Sciences, Jinan 250000, Shandong, China. ${ }^{7}$ School of Animal and Comparative Biomedical Sciences, University of Arizona, Tucson, AZ, USA. ${ }^{8}$ Department of Rheumatology, Qilu Hospital, Cheeloo College of Medicine, Shandong University, Jinan 250012, Shandong, China.

Received: 5 November 2020 Accepted: 2 March 2021

Published online: 10 March 2021

\section{References}

1. Braun J, Baraliakos $X$, Listing J, Sieper J. Decreased incidence of anterior uveitis in patients with ankylosing spondylitis treated with the anti-tumor 
necrosis factor agents infliximab and etanercept. Arthritis Rheum. 2005;52(8): 2447-51.

2. Brophy S, Calin A. Ankylosing spondylitis: interaction between genes, joints, age at onset, and disease expression. J Rheumatol. 2001;28(10):2283-8.

3. Leirisalo-Repo M, Turunen U, Stenman S, Helenius P, Seppälä K. High frequency of silent inflammatory bowel disease in spondylarthropathy. Arthritis Rheum. 1994;37(1):23-31.

4. Souza AS Jr, Müller NL, Marchiori E, Soares-Souza LV, de Souza Rocha M. Pulmonary abnormalities in ankylosing spondylitis: inspiratory and expiratory high-resolution CT findings in 17 patients. J Thorac Imaging. 2004;19(4):259-63.

5. El Maghraoui A, Chaouir S, Abid A, Bezza A, Tabache F, Achemlal L, et al. Lung findings on thoracic high-resolution computed tomography in patients with ankylosing spondylitis. Correlations with disease duration, clinical findings and pulmonary function testing. Clin Rheumatol. 2004;23(2): 123-8.

6. Shimabuco AY, Gonçalves CR, Moraes JCB, Waisberg MG, Ribeiro ACM Sampaio-Barros PD, et al. Factors associated with ASDAS remission in a long-term study of ankylosing spondylitis patients under tumor necrosis factor inhibitors. Adv Rheumatol. 2018;58(1):40

7. Peters MJ, van der Horst-Bruinsma IE, Dijkmans BA, Nurmohamed MT Cardiovascular risk profile of patients with spondylarthropathies, particularly ankylosing spondylitis and psoriatic arthritis. Semin Arthritis Rheum. 2004; 34(3):585-92.

8. Kumar A, Palfrey HA, Pathak R, Kadowitz PJ, Gettys TW, Murthy SN. The metabolism and significance of homocysteine in nutrition and health. Nutr Metab (Lond). 2017;14:78.

9. Shenoy V, Mehendale V, Prabhu K, Shetty R, Rao P. Correlation of serum homocysteine levels with the severity of coronary artery disease. Indian J Clin Biochem. 2014;29(3):339-44.

10. Homocysteine Studies Collaboration. Homocysteine and risk of ischemic heart disease and stroke: a meta-analysis. Jama. 2002;288(16):2015-22.

11. Loscalzo J. Homocysteine and dementias. N Engl J Med. 2002;346(7):466-8

12. Herrmann M, Peter Schmidt J, Umanskaya N, Wagner A, Taban-Shomal O, Widmann $T$, et al. The role of hyperhomocysteinemia as well as folate, vitamin B (6) and B (12) deficiencies in osteoporosis: a systematic review. Clin Chem Lab Med. 2007:45(12):1621-32.

13. Long Y, Nie J. Homocysteine in Renal Injury. Kidney Dis (Basel). 2016;2(2):807.

14. Capelli I, Cianciolo G, Gasperoni L, Zappulo F, Tondolo F, Cappuccilli M, et al. Folic acid and vitamin B12 administration in CKD, why not? Nutrients. 2019;11(2):383.

15. Sam NB, Zhang Q, Li BZ, Li XM, Wang DG, Pan HF, et al. Serum/plasma homocysteine levels in patients with systemic lupus erythematosus: a systematic review and meta-analysis. Clin Rheumatol. 2020;39(6):1725-36.

16. Shu J, Sun X, Li J, Li F, Tang J, Shi L. Serum homocysteine levels and their association with clinical characteristics of inflammatory arthritis. Clin Rheumatol. 2020;39(11):3295-302.

17. Phelip JM, Ducros V, Faucheron JL, Flourie B, Roblin X. Association of hyperhomocysteinemia and folate deficiency with colon tumors in patients with inflammatory bowel disease. Inflamm Bowel Dis. 2008;14(2):242-8.

18. Wakkee M, Thio HB, Prens EP, Sijbrands EJ, Neumann HA. Unfavorable cardiovascular risk profiles in untreated and treated psoriasis patients. Atherosclerosis. 2007;190(1):1-9.

19. Refsum H, Helland S, Ueland PM. Fasting plasma homocysteine as a sensitive parameter of antifolate effect: a study of psoriasis patients receiving low-dose methotrexate treatment. Clin Pharmacol Ther. 1989; 46(5):510-20.

20. Lazzerini PE, Capecchi PL, Selvi E, Lorenzini S, Bisogno S, Galeazzi M, et al. Hyperhomocysteinemia, inflammation and autoimmunity. Autoimmun Rev. 2007;6(7):503-9.

21. Gao XM, Wordsworth P, McMichael AJ, Kyaw MM, Seifert M, Rees D, et al. Homocysteine modification of HLA antigens and its immunological consequences. Eur J Immunol. 1996;26(7):1443-50.

22. Elsherbiny NM, Sharma I, Kira D, Alhusban S, Samra YA, Jadeja R, et al. Homocysteine induces inflammation in retina and brain. Biomolecules. 2020;10(3):393

23. Wang S, Huang Z, Li W, He S, Wu H, Zhu J, et al. IL-37 expression is decreased in patients with hyperhomocysteinemia and protects cells from inflammatory injury by homocysteine. Mol Med Rep. 2020;21(1):371-8.
24. Pirchl M, Ullrich C, Sperner-Unterweger B, Humpel C. Homocysteine has anti-inflammatory properties in a hypercholesterolemic rat model in vivo. Mol Cell Neurosci. 2012;49(4):456-63.

25. Morimoto M, Shivappa N, de Souza GP, Martini LA, Schuch NJ, Hebert JR, et al. Lack of association between dietary inflammatory index and low impact fractures in the Brazilian population: the Brazilian osteoporosis study (BRAZOS). Adv Rheumatol. 2019;59(1):16.

26. Liu Z, Luo H, Zhang L, Huang Y, Liu B, Ma K, et al. Hyperhomocysteinemia exaggerates adventitial inflammation and angiotensin II-induced abdominal aortic aneurysm in mice. Circ Res. 2012;111(10):1261-73.

27. Su SJ, Huang LW, Pai LS, Liu HW, Chang KL. Homocysteine at pathophysiologic concentrations activates human monocyte and induces cytokine expression and inhibits macrophage migration inhibitory factor expression. Nutrition. 2005;21(10):994-1002.

28. Schroecksnadel K, Frick B, Kaser S, Wirleitner B, Ledochowski M, Mur E, et al. Moderate hyperhomocysteinaemia and immune activation in patients with rheumatoid arthritis. Clin Chim Acta. 2003;338(1-2):157-64.

29. Au-Yeung KK, Woo CW, Sung FL, Yip JC, Siow YL, O K. Hyperhomocysteinemia activates nuclear factor-kappaB in endothelial cells via oxidative stress. Circ Res. 2004;94(1):28-36.

30. Wang G, Siow YL, O K. Homocysteine stimulates nuclear factor kappaB activity and monocyte chemoattractant protein-1 expression in vascular smooth-muscle cells: a possible role for protein kinase C. Biochem J. 2000; 352 Pt 3(Pt 3):817-26.

31. Wang G, Siow YL, O K. Homocysteine induces monocyte chemoattractant protein-1 expression by activating NF-kappaB in THP-1 macrophages. Am J Physiol Heart Circ Physiol. 2001;280(6):H2840-7.

32. Singh Y, Gupta G, Kazmi I, Al-Abbasi FA, Negi P, Chellappan DK, et al. SARS CoV-2 aggravates cellular metabolism mediated complications in COVID-19 infection. Dermatol Ther. 2020:33:e13871.

33. Li JJ, Li Q, Du HP, Wang YL, You SJ, Wang F, et al. Homocysteine triggers inflammatory responses in macrophages through inhibiting CSE-H2S signaling via DNA hypermethylation of CSE promoter. Int J Mol Sci. 2015; 16(6):12560-77.

34. Mao N, Chen JW, Peng WF, Chen LX, Xie X. The relationship of plasma homocysteine levels and the methylenetetrahydrofolate reductase C677T gene polymorphism to Ankylosing spondylitis in a Chinese population. Turk J Rheumatol. 2012;27(3):174-8.

35. Baskan BM, Sivas F, Aktekin LA, Dogan YP, Ozoran K, Bodur H. Serum homocysteine level in patients with ankylosing spondylitis. Rheumatol Int. 2009;29(12):1435-9.

36. Gonzalez-Lopez L, Sanchez-Hernandez JD, Aguilar-Chavez EA, Cota-Sanchez AR, Lopez-Olivo MA, Villa-Manzano Al, et al. Hyperhomocysteinemia in ankylosing spondylitis: prevalence and association with clinical variables. Rheumatol Int. 2008:28(12):1223-8.

37. Wei JC, Jan MS, Yu CT, Huang YC, Yang CC, Tsou HK, et al. Plasma homocysteine status in patients with ankylosing spondylitis. Clin Rheumatol. 2007;26(5):739-42

38. Xu XY, Zhou WH, Xiao CS, Li XF, Wang LY. A clinical study of hyperhomocysteinemia in rheumatological diseases. Zhonghua Nei Ke Za Zhi. 2005:44(2):111-4.

39. Geçene M, Tuncay F, Borman P, Yücel D, Senes M, YIlmaz BK. Atherosclerosis in male patients with ankylosing spondylitis: the relation with methylenetetrahydrofolate reductase (C677T) gene polymorphism and plasma homocysteine levels. Rheumatol Int. 2013:33(6):1519-24.

40. Capkin E, Karkucak M, Akyüz A, Alver A, Turkyilmaz AK, Zengin E. The relationship between plasma homocysteine level and different treatment modalities in patients with ankylosing spondylitis. Rheumatol Int. 2012;32(8): 2349-53.

41. Malesci D, Niglio A, Mennillo GA, Buono R, Valentini G, La Montagna G. High prevalence of metabolic syndrome in patients with ankylosing spondylitis. Clin Rheumatol. 2007:26(5):710-4.

42. van der Linden S, Valkenburg HA, Cats A. Evaluation of diagnostic criteria for ankylosing spondylitis. A proposal for modification of the New York criteria. Arthritis Rheum. 1984;27(4):361-8.

43. Dougados M, van der Linden S, Juhlin R, Huitfeldt B, Amor B, Calin A, et al. The European Spondylarthropathy study group preliminary criteria for the classification of spondylarthropathy. Arthritis Rheum. 1991;34(10):1218-27.

44. Garrett S, Jenkinson T, Kennedy LG, Whitelock H, Gaisford P, Calin A. A new approach to defining disease status in ankylosing spondylitis: the bath 
ankylosing spondylitis disease activity index. J Rheumatol. 1994;21(12):2286-

91.

45. Moher D, Liberati A, Tetzlaff J, Altman DG. Preferred reporting items for systematic reviews and meta-analyses: the PRISMA statement. PLoS Med. 2009;6(7): 1 1000097.

46. Stang A. Critical evaluation of the Newcastle-Ottawa scale for the assessment of the quality of nonrandomized studies in meta-analyses. Eur J Epidemiol. 2010;25(9):603-5.

47. Luo D, Wan X, Liu J, Tong T. Optimally estimating the sample mean from the sample size, median, mid-range, and/or mid-quartile range. Stat Methods Med Res. 2018;27(6):1785-805.

48. Wan X, Wang W, Liu J, Tong T. Estimating the sample mean and standard deviation from the sample size, median, range and/or interquartile range. BMC Med Res Methodol. 2014;14:135.

49. Higgins JP, Thompson SG, Deeks JJ, Altman DG. Measuring inconsistency in meta-analyses. BMJ. 2003;327(7414):557-60.

50. Deeks JJ, Higgins JP, Altman DG, Group obotCSM. Analysing data and undertaking meta-analyses. Cochrane Handb Syst Rev Intervent. 2019. p. 241-84.

51. Wållberg-Jonsson S, Cvetkovic JT, Sundqvist KG, Lefvert AK, RantapääDahlqvist $\mathrm{S}$. Activation of the immune system and inflammatory activity in relation to markers of atherothrombotic disease and atherosclerosis in rheumatoid arthritis. J Rheumatol. 2002;29(5):875-82.

52. Lopez-Olivo MA, Gonzalez-Lopez L, Garcia-Gonzalez A, Villa-Manzano Al, Cota-Sanchez AR, Salazar-Paramo M, et al. Factors associated with hyperhomocysteinaemia in Mexican patients with rheumatoid arthritis. Scand J Rheumatol. 2006;35(2):112-6.

53. Lazzerini PE, Capecchi PL, Bisogno S, Galeazzi M, Marcolongo R, Pasini FL. Reduction in plasma homocysteine level in patients with rheumatoid arthritis given pulsed glucocorticoid treatment. Ann Rheum Dis. 2003;62(7): 694-5.

54. Hornung N, Ellingsen T, Stengaard-Pedersen K, Poulsen JH. Folate, homocysteine, and cobalamin status in patients with rheumatoid arthritis treated with methotrexate, and the effect of low dose folic acid supplement. J Rheumatol. 2004;31(12):2374-81.

55. van Ede AE, Laan RF, Blom HJ, Boers GH, Haagsma CJ, Thomas CM, et al. Homocysteine and folate status in methotrexate-treated patients with rheumatoid arthritis. Rheumatology (Oxford). 2002;41 (6):658-65.

56. Selhub J, Dhar GJ, Rosenberg IH. Inhibition of folate enzymes by sulfasalazine. J Clin Invest. 1978;61(1):221-4.

57. Wan L, Li Y, Zhang Z, Sun Z, He Y, Li R. Methylenetetrahydrofolate reductase and psychiatric diseases. Transl Psychiatry. 2018;8(1):242.

58. Fowler B. Disorders of homocysteine metabolism. J Inherit Metab Dis. 1997; 20(2):270-85.

59. Goyette P, Sumner JS, Milos R, Duncan AM, Rosenblatt DS, Matthews RG, et al. Human methylenetetrahydrofolate reductase: isolation of CDNA, mapping and mutation identification. Nat Genet. 1994;7(2):195-200.

60. Gallistl S, Sudi K, Mangge H, Erwa W, Borkenstein M. Insulin is an independent correlate of plasma homocysteine levels in obese children and adolescents. Diabetes Care. 2000;23(9):1348-52.

61. Ganguly P, Alam SF. Role of homocysteine in the development of cardiovascular disease. Nutr J. 2015;14:6.

62. Zhang S, Bai YY, Luo LM, Xiao WK, Wu HM, Ye P. Association between serum homocysteine and arterial stiffness in elderly: a community-based study. J Geriatr Cardiol. 2014;11(1):32-8.

63. Schieir O, Tosevski C, Glazier RH, Hogg-Johnson S, Badley EM. Incident myocardial infarction associated with major types of arthritis in the general population: a systematic review and meta-analysis. Ann Rheum Dis. 2017; 76(8):1396-404

64. Mathieu S, Soubrier M. Cardiovascular events in ankylosing spondylitis: a 2018 meta-analysis. Ann Rheum Dis. 2019:78(6):e57.

65. Agca R, Heslinga SC, Rollefstad S, Heslinga M, Mclnnes IB, Peters MJ, et al. EULAR recommendations for cardiovascular disease risk management in patients with rheumatoid arthritis and other forms of inflammatory joint disorders: 2015/2016 update. Ann Rheum Dis. 2017;76(1):17-28.

66. Suissa S, Bernatsky S, Hudson M. Antirheumatic drug use and the risk of acute myocardial infarction. Arthritis Rheum. 2006;55(4):531-6.

\section{Publisher's Note}

Springer Nature remains neutral with regard to jurisdictional claims in published maps and institutional affiliations.

\section{Ready to submit your research? Choose BMC and benefit from:}

- fast, convenient online submission

- thorough peer review by experienced researchers in your field

- rapid publication on acceptance

- support for research data, including large and complex data types

- gold Open Access which fosters wider collaboration and increased citations

- maximum visibility for your research: over $100 \mathrm{M}$ website views per year

At BMC, research is always in progress.

Learn more biomedcentral.com/submissions 